\title{
The START Project
}

\author{
Alexander Gurievich Marchuk \\ A.P. Ershov Institute of Informatics Systems of SB RAS \\ Acad. Lavrentiev Ave., 6, Novosibirsk 630090 \\ mag@iis.nsk.su
}

\begin{abstract}
The paper overview one of the projects at the middle 80-th, supported by USSR government and oriented on breakthrough in hardware/software development. Several academic groups with industrial companies fulfilled a lot of investigations, built prototypes of perspective computers and intellectual programs. Author, as one of participants and headers of START project, analyses some principles of the project organizing structure. Although most brilliant results of START project were not used by industry because of economic and political crisis in Soviet Union, the impact of enthusiastic work and generating new ideas, was great for all major developers. Several opinions of participants are presented in conclusion.
\end{abstract}

Keywords: START, Modular asynchronous evolutionary systems, Kronos workstation, development of computing systems, hardware development, software development.

\section{The Beginning}

The temporary scientific and technical group START was created in 1985 by a joint decision of the Academy of Sciences and the State Commission on Science and Technology for a period of three years. The resolution [1] holds: "For the purpose of development and experimental testing of the elements of the fifth-generation computer concept..."

The resolution was preceded by the launch of Japan's national project of the creation of the fifth-generation computers in early 1980s. The land of the rising sun, having achieved substantial positions in the world automobile and home appliance industries, would not tolerate its meek results in computer engineering. Best minds and immense funds were directed at the solution of this breakthrough task.

The State Commission on Science and Technology wanted to find out how serious a threat was hidden in the Japanese project. The formed a working group headed by V. Kotov, the SB AS Computing Center deputy director at the time. The group included leading specialists of the Academy in the fields of computing engineering, software and artificial intelligence systems, as well as representatives of the industry. The group had a task - not only to evaluate the scientific advisability and technological feasibility of the Japanese project, but also to propose a concept of developing computers and software in the USSR.

It was a unique chance. The thing is that after the emergence of first computers, in which specialists from academic institutes participated immediately (with a creative 
peak in mid-sixties in the form of the BESM-6 computer), the Academy of Sciences was "unchurched" from computer engineering; occasional teams were busy with innovations in programming. The result was the country getting its ES and SM computers that did not make a single step forward, but on the contrary, they cemented our technology lag. The new developments such as Elbrus and PS-2000 already did not seem revolutionary enough. The working group, which included such acknowledged specialists as E.H. Tyugu, Yu.G. Evtushenko, V.E. Kotov, A.S. Nariniani, V.M. Bryabin, and young but feathered researchers and developers who gathered from different towns and research groups of the USSR, took up the research enthusiastically. Due to security restrictions we had to work in complete isolation for a month; the result was an extended concept report that unfortunately was classified secret.

I remember well that there was no serious disagreement, not to say conflicts. There was a creative atmosphere, scientific analysis, and respect for the opinions of each other. Our report said very little of the Japanese project - we did not even want to criticize its flaws. The future has shown our rightness, and that the Japanese "wonder" had little practical effect. By the way, leading Western countries started their own national programs in response to the Japanese one, and their results turned out far more important. Our enthusiasm and creativity were fueled by the sensation of the beginning of large-scale, useful work.

The principles and outlines of solutions in our concept showed a direction (we concentrated on just one), which would later be called IT - information technologies. Without getting too deep into the technical details, let's say that we proposed a scheme of building user-oriented computers and software. On the top of the thenvirtual structure rested the "brand-new" intellectualization tools.

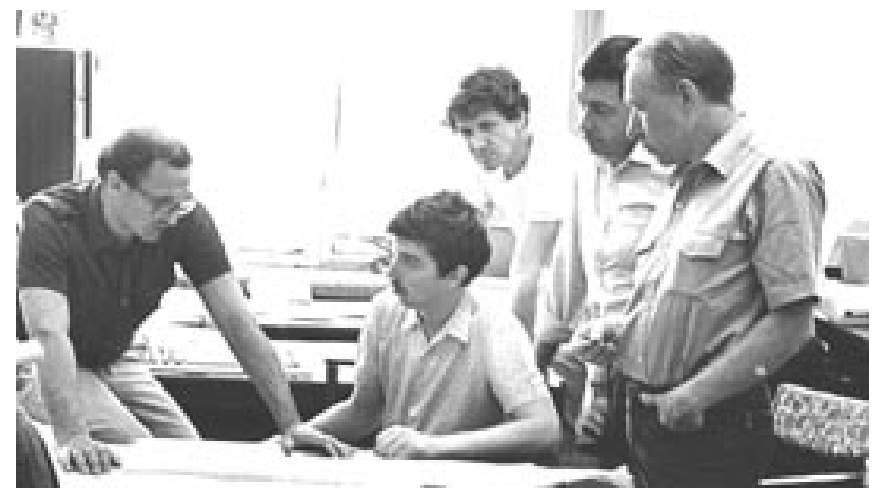

Fig. 1. Alexander Marchuk with colleagues

I must remark that the core of the working group consisted of representatives of the Novosibirsk Computing Center: V.E. Kotov, A.S. Narinyani, E.P. Kuznetsov, and A.G. Marchuk. What underlay this trust? The reason was the MARS project (Modul'nye Asinkhronnye Razvivaemye Sistemy - Modular asynchronous evolutionary systems), which started in the SB AS Computing Center in 1982, and in three years noticeable results had been achieved. The concept of MARS was 
acknowledged in the scientific circles, the design of MARS-M supercomputer was underway, business connections were established with industry organizations in Moscow, Severodonetsk, and Kiev. The report we prepared was presented, studied and received support in the State Commission on Science and Technology, Academy of Sciences and related ministries. The result was that we were proposed to form a temporary (for a period of three years) team of developers to implement the proposed concept - the START Temporary Science and Technology Group.

\section{Work}

The core of START was composed of teams headed by the main participants of the working group. It was not due to current situation; it was because during the concept development we realized that our views on the aims coincided and that we complemented each other well and could work together. The group was substantially decentralized. The largest part of the group was located in Novosibirsk; it included specialists from the SB AS Computing Center, developers and designers from the Novosibirsk Branch of the Institute of Precise Mechanics and Computing Engineering, Special Design Bureau of Computing Engineering (now Design and Technology Institute of Computing Engineering), Independent Applied Laboratory of the Ministry of Instrument Making. In Moscow, the group included scientists and developers from the AS Computing Center and was headed by Yu.G. Evtushenko (currently an academician and director of the RAS Computing Center), and V.M. Bryabin. The Tallinn group united specialists from the Estonian AS Institute of Cybernetics and Special Design Bureau. Later, START was expanded by means of the Kiev "Microprocessor" Production Company. When necessary, specialists from other cities and organizations were invited. In different points in time, START included from 200 to 300 people.

The task was very specific: to develop and create a set of hardware tools and software defined by requirements specification. It meant pioneering developments done at the highest up-to-date international level. Such a problem could be solved in such short time only by an energetic, enthusiastic young team. We had it all in full volume. Verdant youth was involved both in research and research management; their opinion was always respected and considered. I, thirty-three at the time and in the position of vice-leader of the project, already felt like an old wizard.

The energy and creative spirit of the youth was fully expressed in the Kronos team. Kronos is the name of a 32-digit computer developed by NSU students, one of the first microcomputers in its class. Kronos is a legend which began before START. Kronos remains a legend, with a hint of nostalgia over youth, for all those who were involved in this extraordinary event.

Perhaps the story began at the Young Technicians Club of Akademgorodok, where Zhenia Tarasov and Volodya Filippov worked in different laboratories on a processor and a video display, respectively. In Kazakhstan Republic Dima Kuznetsov learned programming from books, because there were no computers in their town then. Or perhaps, it all started in the Physics Department dormitory of the NSU, where Zhenia and Volodia united their creativity; then teamed with Volodya Vasekin and "real" programmers from the Mathematics department - Dima (a sophomore) and Alexei 
Nedorya (a junior); together, they started a club called Intruder. Figure 2 shows some of these technicians.

For me - and the story I'm telling - it all began in 1983, when the mentioned characters, at the time juniors of the Novosibirsk State University - only Alexei was a senior - came to me and declared: "We want to create a 32-digit computer! We know how to do that." I had nothing left but to support them - the kids were just too good. Youthful boldness combined with the fundamental knowledge NSU provides makes wonders if you manage to see in young people talent, enthusiasm, and literacy, and trust and help them afterwards. Wonders did happen - Zhenya defended the second (!) version of the Kronos processor as his graduation thesis, and Dima presented a cross-compilation system for this computer. By the way, Kronos- 2 was replicated in as many as a hundred copies, because many wanted to have a "real" 32-digit computer and it had become available. Soldering and tuning was the duty of Volodya Filippov - and he still enjoys soldering, even though he has become the deputy director of the IIS.

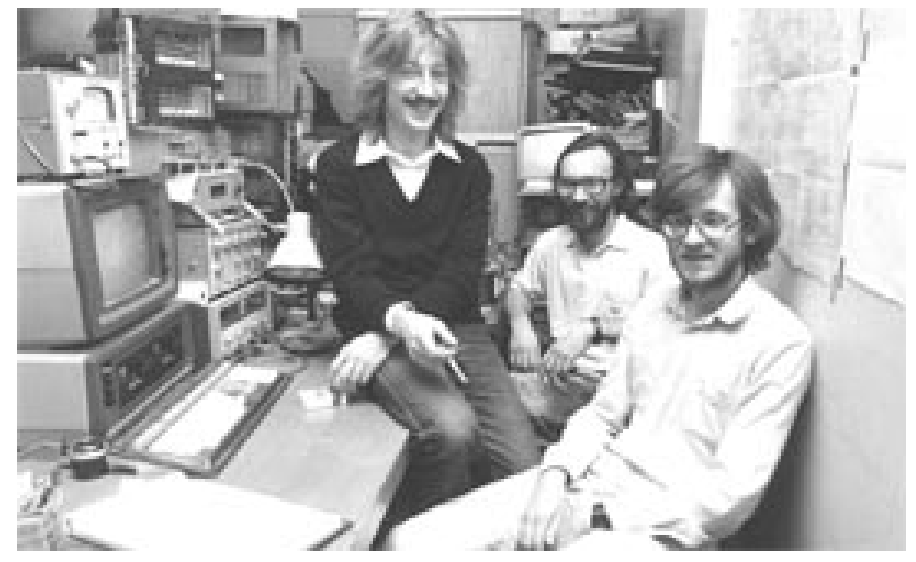

Fig. 2. The Kronos Group: Dmitry Kuznetsov, Alexei Nedorya, Yevgeni Tarasov

An important peculiarity of the Kronos project was its exceptional attractiveness for talented students. I have never seen another young team so efficient and selforganized. On the forty square meters assigned for the project, something was always being programmed and discussed day and night, more and more new students joined the team and were assigned tasks, and in little time they became veterans of the Kronos movement. About thirty people took part in the project. I must say that all of them achieved high professional level and now lead their own teams - in different organizations, cities, and countries.

Returning to the START project, it was important to organize the work properly and achieve its efficacy. Modern generations of programmers can hardly imagine the limited conditions in which programs were developed in the 1970s and the 1980s. To improve substantially the instrumental support of the development it was decided to buy foreign computing machines. Not all remember that at the time the USA cast a strict embargo on sales of modern machines, including computers, to the USSR. 
Hence, Australian-made personal computers and workstations were bought. Despite its disadvantages, the Australian computers were instrumental in solving the problems, since they allowed working (at least in programming) on a quite high technical level. I will not list the things we lacked, compared to our foreign colleagues, because even the capacities of "elite" machines were very limited; this lack was well compensated by the enthusiasm and professionalism of the developers.

The work was organized by team contract method, i.e. a team took a certain task under collective responsibility. Hence, the relationships within the teams were very democratic, and the team leader performed mostly provisional and external coordinating role, rather than keeping to regular directorial duties.

Key elements in the START activities were the annual January meetings in Ivanteevka. Ivanteevka is a small industrial city near Moscow, where START activists gathered in summer house areas for mutual reporting, planning and coordination. Why January? Perhaps because our first meeting took place before the official start of the project, when we formed and defined exactly the requirements specification, which served as basis for official documents that were being prepared for the first of April. It later became a tradition.

"Ivanteevka", as we called our meeting, was a one-of-a-kind conference. Machinery was brought - computers, working samples, an overhead projector (a true novelty at the time!), the work was organized in such a way that we could really discuss, report and immediately make changes to our results, develop prototypes. This was a real two-week creative workshop, where everyone made his valuable contribution to the discussion and realization of general and special issues. We never had time to sleep; luckily, we all were young and full of energy. A huge project never develops linearly, there is always a need for substantial corrections, and those corrections were made, having been thoroughly discussed every time. For example, it was intended initially that a product of the Tallinn design bureau, made from standard components, be used as the basis of the Kronos. However, after the high results of joint evaluation of the students' Kronos project it was decided to reengineer Kronos according to the project and industry specifications and use it as the basis for workstations produced in Tallinn and a model of super-mini-PC that was being developed in Novosibirsk.

In addition to other things, Ivanteevka facilitated personal friendship in our distributed team. This friendship goes on today, having turned into a kind of "fraternity". No matter where you go, if there are ex-START people, you will be infinitely welcome, and there will be no end to warm memories.

START did not go unnoticed by the press and television. Their attention was, however, quite special - seeing a "wonder" and telling about a wonder, but not about good, wisely organized professional work. Repeatedly we asked the reporters to show us their texts at least for minor technical examination - and not a single time they considered it necessary. They would write all sorts of nonsense... Official authorities also liked to use our materials for solving their own problems, but things said from the tribunes reflected the state of affairs very roughly. For example, Mikhail Gorbachev, the Communist Party General Secretary of the time, told at a regular meeting of VLKSM (Leninist Young Communist League of the Soviet Union), that a team of researchers headed by a young Dr. Kotov (it's hard to believe the young communists would think of a fifty-year-old as a young man) created a supercomputer 
capable of performing 100 million operations per second. We did not have such tasks set before us.

Yet we could not find solutions for the social problems young people inevitably face. The housing provision system was so crisis-ridden that every single place in a dormitory or an apartment cost us a grand battle and did not at all improve the overall situation. The lasting suspense of domestic problems served as one of the substantial reasons of the massive flight of our young talents abroad.

\section{Results}

Exactly at the target date, at the end of the three years, a government resolution created the State interdepartmental commission for the acceptance of work completed by START. We had things to show.

The following is a partial list of results presented to the commission.

- A four-processor working model of MARS-T multiprocessor complex, built on the basis of the developed processors Kronos 2.6, equipped with a multiprocessor multi-program operating system that we developed, which successfully completed the given test parallel programs;

- The PIRS workstation equipped with a full set of system software, including two operating systems, Unix and Excelsior (a product of the Kronos group), supplied with a software package sufficient for numerous applications;

- BARS parallel programming language, Polar architecture design language, and NUT programming system, providing new intellectualization tools;

- A set of programs for Specter workstations and personal computers;

- Modula-2, C++ and Fortran compilers;

- VLSI CAD system; graphic tools, engineering CAD system - the list continues.

The first two years of START showed that something brand new, worthy of replication and application in the national economy was being developed. That's why on the final stage we invited fresh teams of constructors, industrial software designers and microprocessor designers. It was decided to aim at the future prospects, involving into the introduction process special institutes, design bureaus, and plants. In the result, the completion of START didn't mean the end of works, because research had turned into development and creation of special systems. Scientific and creative contacts multiplied and spread over cities and countries, primarily within the COMECON countries. We planned that:

- Kronos be installed as on-board computer of airplanes and space vehicles, and the development of the microprocessor set went into its final phase;

- The production of workstations and parallel computers attracted the attention of all sorts of businesses;

- Software was introduced and multiplied on all kinds of platforms, including the then-new PCs;

- CAD systems were adapted to rigid conditions of industrial design. 
Unfortunately, many of our intentions never found any development due to the economical and political collapse of the late eighties. Nevertheless, a noticeable proportion of our products found its place in the new conditions. Analyzing our results, I see the most important achievement not in the final product, but in scientific results and creative professional growth of the people for whom START was not only work, but also a time of steadfast headway, a time of establishing oneself as a specialist and leader. Life scattered STARTers all over the world, but most of us retained our loyalty to professional duty and calling. Our relationship remains friendly and warm. Science is an international business, and both those of us who happen to work abroad and those who work in the Russian IT industry do the same thing, recalling our youth as an example of fine work.

\section{Opinions of Participants about START}

Enn Haraldovich Tyugu, Institute of Cybernetics, Tallinn, Estonia: “The NUT programming environment http://cs.ioc.ee/ nut/ was gradually tuned up to the state of ready product. Its application yielded a number of interesting scientific results, and it is still used by researchers for modeling complex dynamic processes" [3].

Vitaly Telerman, currently a leading developer in Dassault Systèmes, France: "On the one hand you can say that the results achieved in START 15 years ago have finally been implemented into the industry, somewhat "French-style", perhaps. Unfortunately, not everything has been done, some things are only starting to be taken seriously by developers; much remains unused in practice". [2]

Viktor Mikhailovich Briabrin, Broad Street Software Group, Мериленд, США: "In the days of START, everything was devised and implemented on the spot with creativity, skill, elegance, and enthusiasm thanks to the talent and professionalism of our fellow workers and postgraduates - participants of the project. Of course, it can be said about most of the START project members - in Moscow, Novosibirsk, and Tallinn". [4]

Vadim Evgenievich Kotov, Carnegie-Mellon University, USA: "After some creative re-thinking, I pursued the ideas of modular asynchronous evolutionary systems, which served as a basis for START, in my work at Hewlett-Packard Laboratories on Systems of Systems architecture. These works led to the emergence of Service-Oriented Architecture, in which all levels from top to bottom are federations of independent interacting components - services located in a networkfederation of independent servers. I use the same approach in our current works on the creation of high-reliability systems for NASA". [5]

Alexander Semyonovich Narinyani, Russian Scientific Research Institute of Artificial Intelligence, Moscow: "our greatest adventure was the summer that we spent in Gury Ivanovich Marchuk's office, developing the project concept and calling up a whole crowd of experts and administration officials for the discussion of different aspects of this challenging document". [6]

Andrei Khapugin, Excelsior, Ltd.: "Most often I recall an article from, as far as I remember, Komsomolskaya Pravda about the Kronos group, which started with words: "Dmitry Kuznetsov at 25 is a super-programmer of the international level, and 
he is completely aware of that". They didn't give him a minute of peace for weeks afterward...". [7]

Acknowledgment. This paper is essentially based on an article published in the Nauka v Sibiri (Science in Siberia) newspaper [8].

\section{References}

1. Resolution of State Committee on Science and Technology and Presidium of the USSR Academy of Sciences (March 19, 1985), 101/48

http://start.iis.nsk. su/archive/eaindex. asp? lang=1\&did=23849

2. Telerman, V.: Recollections about START, http://start.iis.nsk.su/persons/telerman/index.shtml

3. Tyugu, E.: START in Tallinn and all that ensued, http://start.iis.nsk.su/persons/tyugu/index.shtml

4. Briabrin, V.M.: SPEKTR Project, http://start.iis.nsk.su/persons/bryabrin/index.shtml

5. Kotov, V.E.: Answers to the questionnaire, http://start.iis.nsk.su/persons/questionnaire/kotov. shtml

6. Narinyani, A.S.: Answers to the questionnaire, http://start.iis.nsk.su/persons/questionnaire/narinyani.shtml

7. Khapugin, A.: Answers to the questionnaire, http://start.iis.nsk.su/persons/questionnaire/khapugin.shtml

8. Marchuk, A.G.: 20th Anniversary of Legendary START Project, Nauka v Sibiri, no. 16 (2502) (April 2005) 